\title{
Metabolic and Genetic Diversity of Mesophilic and Thermophilic Bacteria Isolated from Composted Municipal Sludge on Poly- $\varepsilon$-caprolactones
}

\author{
Igor Tiago, ${ }^{1}$ Isabel Teixeira, ${ }^{2}$ Sílvia Si1va, ${ }^{2}$ Paula Chung, ${ }^{1}$ António Veríssimo, ${ }^{1}$ Célia M. Manaia ${ }^{2}$ \\ ${ }^{1}$ Departamento de Zoologia and Centro de Neurociências e Biologia Celular, Universidade de Coimbra, 3004-517 Coimbra, Portugal \\ ${ }^{2}$ Escola Superior de Biotecnologia, Universidade Católica Portuguesa, 4200-072 Porto, Portugal
}

Received: 22 March 2004 / Accepted: 19 May 2004

\begin{abstract}
Thirty mesophilic and thermophilic bacteria were isolated from thermobiotically digested sewage sludge in culture medium supplemented with poly- $\varepsilon$-caprolactone (PCL). The ability of each purified isolate to degrade PCL and to produce polymer-degrading extracellular enzymes was assessed. Isolates were characterized based on random amplified polymorphic DNA (RAPD), 16S rDNA sequence-based phylogenetic affiliation and carbohydrate-based nutritional versatility. Mesophilic isolates with ability to degrade PCL were attributed to the genera Acinetobacter, Burkholderia, Pseudomonas, and Staphylococcus. Thermophilic isolates were members of the genus Bacillus. Despite the restricted phylogenetic and genotypic diversity observed for thermophiles, their metabolic versatility and wide range of growth temperatures suggest an important activity of these organisms during the whole composting process.
\end{abstract}

Thermophilic digestion of sewage sludge is considered an effective process for degradation of organic matter and promotion of water evaporation from solid materials, with the simultaneous elimination or reduction of pathogenic microorganisms [20, 21]. Considering the metabolic transformations that take place during composting [20] it is expected that the resultant compost will contain thermotolerant and thermophilic microorganisms able to degrade a variety of organic compounds, mainly polymeric substances.

This study was designed to compare the diversity of thermophilic and mesophilic bacteria that could be isolated from sludge compost, using synthetic medium supplemented with poly- $\varepsilon$-caprolactone polymers. Isolation was performed at $30^{\circ} \mathrm{C}$ and at $50^{\circ} \mathrm{C}$, resulting in the purification of 16 mesophilic and 14 thermophilic bacteria. Under the isolation conditions used, the genetic and phylogenetic diversity of thermophiles was reduced compared with that of mesophiles, although the meta-

Correspondence to: Célia M. Manaia; email: celman@esb.ucp.pt bolic versatility and temperature range of growth of thermophiles suggest that this physiological group of organisms may play an important role in thermophilic digestion.

\section{Materials and Methods}

Chemicals. Culture media complex nutrients and agar were obtained from LabM, Amersham, UK; chemical reagents were obtained from Merck, Darmstadt, Germany; and the poly- $\varepsilon$-caprolactone (PCL) (Capa 2054 and Capa 4101) were obtained from Solvay, UK.

Enumeration and isolation of organisms. Samples were collected from a sludge thermophilic aerobic digester in a domestic wastewater treatment plant. In this treatment process, the anaerobic digest of decanted sludge was mixed with granular pine bark and submitted to windrow composting. The windrow process had additional induced aeration, occurred for 20 days and reached a maximal temperature of about $60^{\circ} \mathrm{C}$. Samples were collected on the 19th day. Four samples of compost were collected within an interval of 5 months. Ten grams of each compost sample was suspended in $100 \mathrm{~mL}$ of demineralized water, serially diluted, and plated onto PCL-containing medium (PCLM) [15], a mineral medium supplemented with $0.2 \mathrm{~g} / \mathrm{L}$ of yeast extract and $2.5 \mathrm{~g} / \mathrm{L}$ of PCL. Two PCL were used: (1) Capa 2054, a 


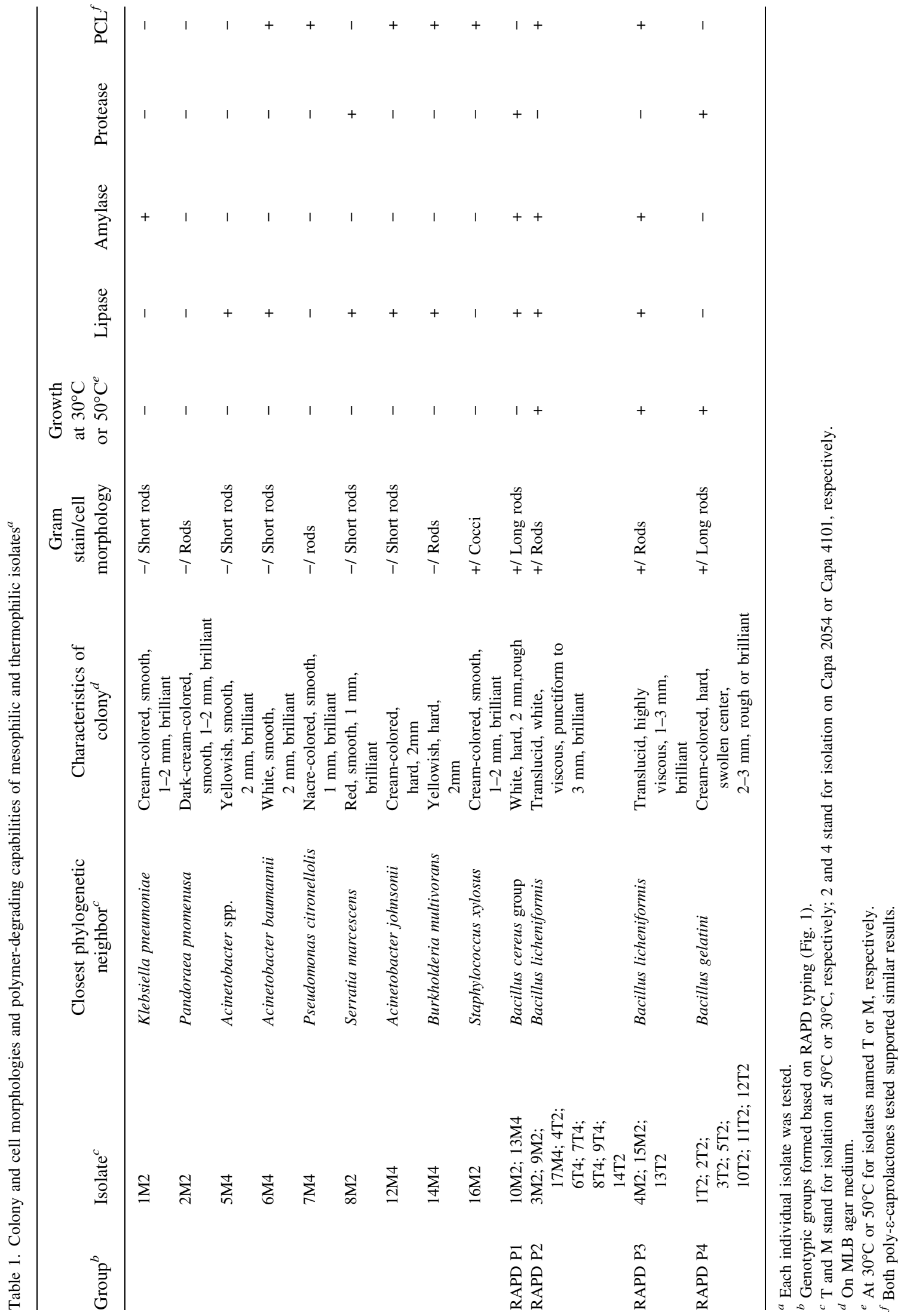




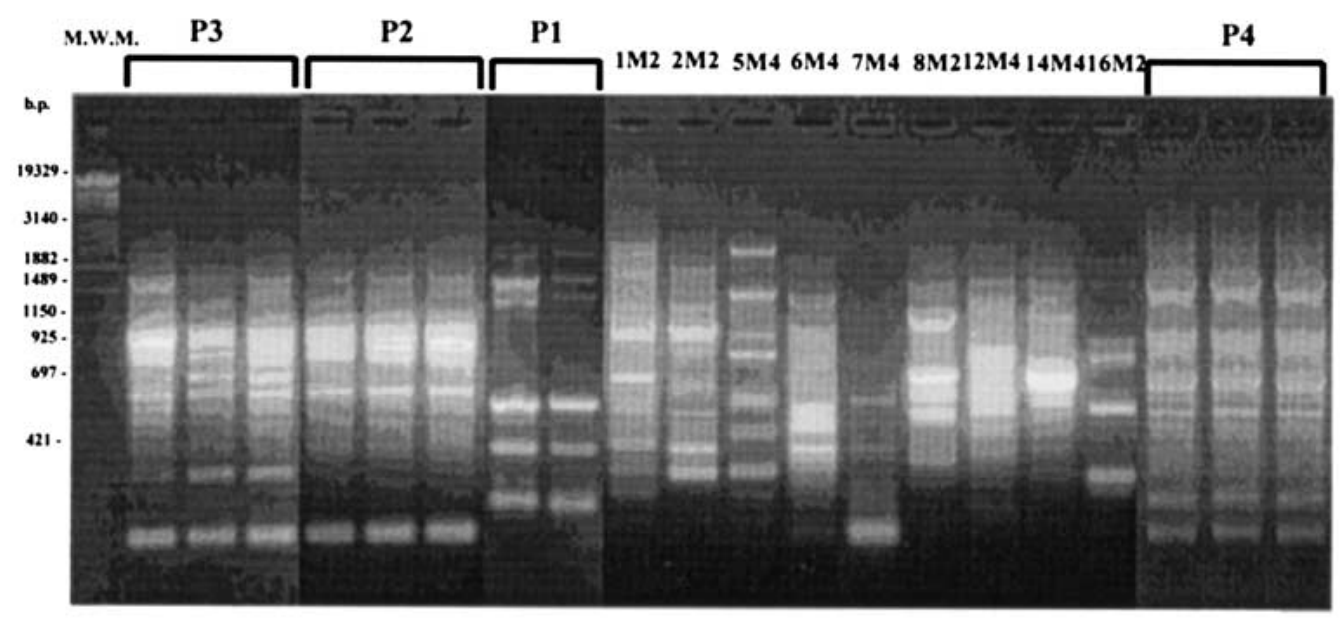

Fig. 1. Profiles of random amplified polymorphic DNA (RAPD) of bacterial isolates. The correspondence of the RAPD profiles (P1, P2, P3, and P4) and the respective grouped isolates is shown in Table 1.

linear polyester diol-derived caprolactone, terminated by primary hydroxyl groups, with a mean molecular weight of 550; (2) Capa 4101, a tetra-functional polyol, terminated by primary hydroxyl groups, with a mean molecular weight of 1000 . Colony forming units (CFU) were enumerated on medium containing either of the PCL used, after $24 \mathrm{~h}$ of incubation at $30^{\circ} \mathrm{C}$ or $50^{\circ} \mathrm{C}$.

For the isolation of PCL-degraders, cultures on PCLM were examined for the presence of distinct morphotypes after $24 \mathrm{~h}, 48 \mathrm{~h}, 7$ days, and 15 days of incubation. A single isolate of each, apparently distinct, morphotype was isolated for further purification and characterization (Table 1). During the subsequent samplings, the same procedure was used, selecting new apparent morphotypes, in order to screen the maximal diversity of PCL-degraders. Each organism was purified by subculturing on modified Luria-Bertani (MLB) agar, containing (per liter): $5.0 \mathrm{~g}$ tryptone, $2.5 \mathrm{~g}$ yeast extract, $1.0 \mathrm{~g} \mathrm{NaCl}$, and $15 \mathrm{~g}$ agar. Purified cultures were cryopreserved in MLB broth supplemented with $15 \%$ (v/v) of glycerol.

Phenotypic characterization of the isolates. Each purified isolate was designated by a 3-digit code: a number for the isolate; $\mathrm{M}$ or $\mathrm{T}$, for isolation at $30^{\circ} \mathrm{C}$ or at $50^{\circ} \mathrm{C}$, respectively; and 2 or 4 , for isolation on Capa 2054 or Capa 4101, respectively. Unless otherwise stated, phenotypic characterization was performed using MLB agar and each organism was cultivated at the respective temperature of isolation. Each isolate was characterized for colony and cell morphology and Gram staining according to the methods described by Doetsch [4]. The ability of each purified isolate to degrade Capa 2054 or Capa 4101 was assessed using the isolation medium referred to above and was considered positive whenever a clear zone around the colony was observed. The production of extracellular enzymes was assessed according to Smibert and Krieg [26]. Briefly, the production of amylases was assayed in MLBA agar supplemented with $5.0 \mathrm{~g} / \mathrm{L}$ of soluble starch; the production of lipases was assayed in MLB agar supplemented with $2.0 \mathrm{~g} / \mathrm{L}$ of $\mathrm{CaCL}_{2}$ and $10 \mathrm{~g} / \mathrm{L}$ of Tween-80; and the production of proteases was assayed in MLB broth supplemented with $50.0 \mathrm{~g} / \mathrm{L}$ of gelatin. The metabolic pattern of selected isolates (see below) was characterized using the API 50 $\mathrm{CH}$ system (Biomerieux) and the defined medium (B) described previously [15].
Genotypic characterization of the isolates. Random amplified polymorphic DNA (RAPD) analysis was used as a preliminary method to group bacterial isolates. Crude cell lysates were used as DNA templates as described by Wiedman-al-Ahmad et al. [33]. Amplification reactions were performed with a total volume of $50 \mu \mathrm{L}$ containing: $1.5 \mathrm{U}$ of $\mathrm{Taq}$ polymerase, $1.5 \mathrm{~mm} \mathrm{MgCl}_{2}$ (Pharmacia Biotech), $0.2 \mathrm{~mm}$ each dNTP, $0.6 \mu \mathrm{M}$ primer OPA3 (5'AGTCAGCCAC- $3^{\prime}$ ), and $2.0 \mu \mathrm{L}$ of crude cell lysates. Samples were subjected to 45 cycles of amplification (Perkin-Elmer, model 240) as follows: $1 \mathrm{~min}$ at $94^{\circ} \mathrm{C}, 1 \mathrm{~min}$ at $34^{\circ} \mathrm{C}, 2 \mathrm{~min}$ at $72^{\circ} \mathrm{C}$, and a final extension step of $7 \mathrm{~min}$ at $72^{\circ} \mathrm{C}$. Polymorphic DNA fragments were analyzed by electrophoresis in $2 \%$ agarose gel in Tris-acetate-EDTA buffer [24].

Phylogenetic analysis. A single isolate of each RAPD-based group and non-grouped strains were further characterized by $16 \mathrm{~S}$ rRNA gene sequence analysis. The extraction of genomic DNA, PCR amplification and sequencing of the I6S rRNA gene were carried out as described previously [23]. DNA sequences were determined using a model 310 Genetic Analyzer (Applied Biosystems, Foster City, CA).

The quality of $16 \mathrm{~S}$ rRNA gene sequences was checked manually using Bioedit editor [7] and aligned against representative reference sequences of the most closely related members, obtained from the Ribosomal Database Project [13] and EMBL, using the multiplealignment CLUSTAL X software package [31]. The method of: Jukes and Cantor [9] was used to calculate evolutionary distances; phylogenetic dendrograms were constructed using the neighbor-joining method, and tree topologies were evaluated by performing bootstrap analysis [5] of 1000 data sets by using the MEGA2 package [11].

\section{Results and Discussion}

Isolation of thermophilic and mesophilic PCLdegraders. The frequency of isolates recovered on PCLM agar at $30^{\circ} \mathrm{C}$ and $50^{\circ} \mathrm{C}$ after $24 \mathrm{~h}$ of incubation was assessed using three independent samples collected within an interval of 5 months. At both isolation 

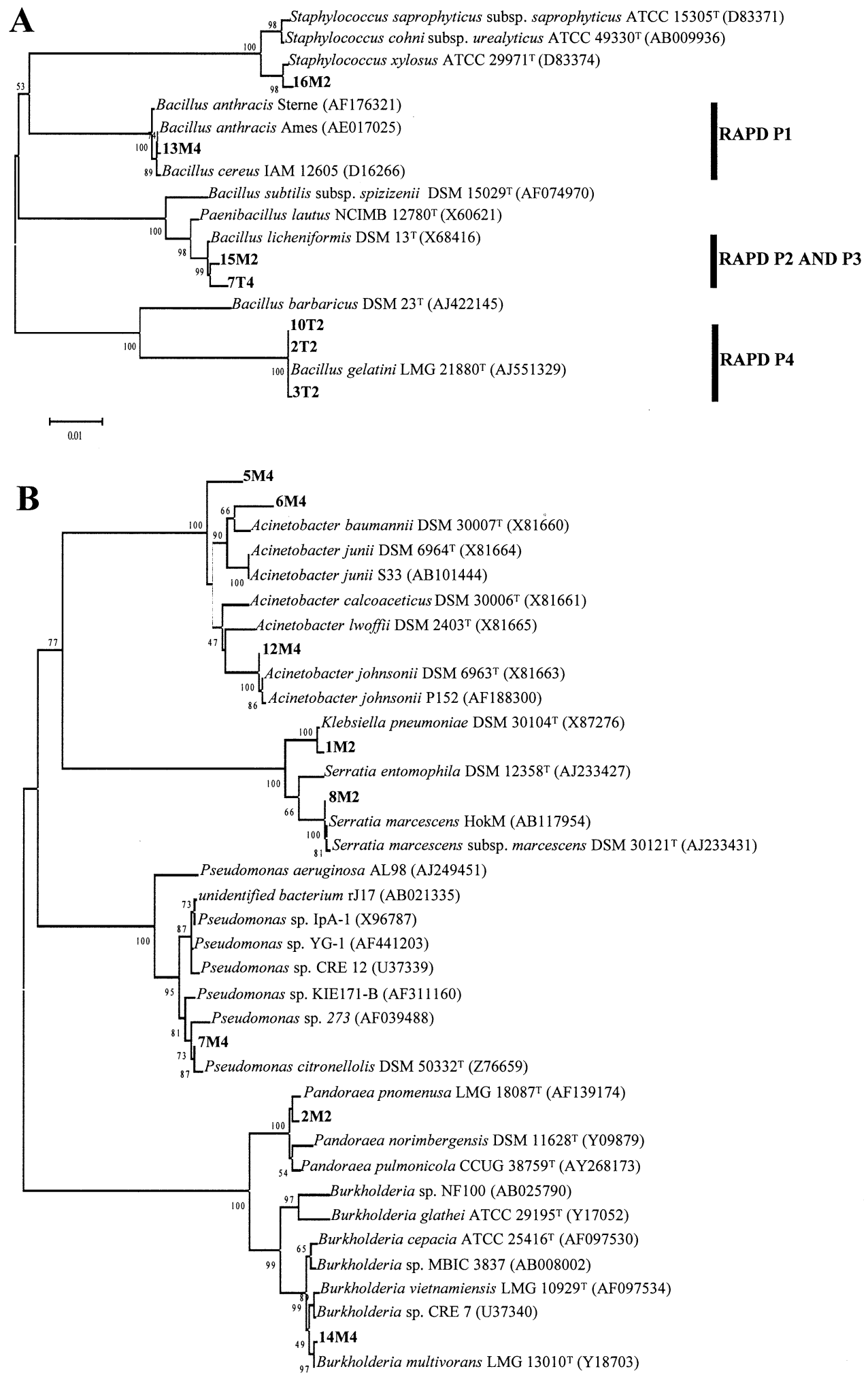

0.02

Fig. 2. Phylogenetic dendrograms based on a comparison of the $16 \mathrm{~S}$ rDNA sequences of the Gram-positive isolates (A) and Gram-negative isolates (B) and some of their closest phylogenetic relatives. The trees were created using the neighbor-joining method. The numbers on the tree indicate the percentages of bootstrap sampling, derived from 1000 replications. Isolates characterized in this study are indicated in bold. The bar represents relative sequence divergence. 
Table 2. Carbohydrate-based nutritional pattern of mesophilic and thermophilic isolates (+, growth; -, no growth)

\begin{tabular}{|c|c|c|c|c|c|c|c|c|c|c|c|}
\hline Carbon source ${ }^{a}$ & $1 \mathrm{M} 2$ & $5 \mathrm{M} 4$ & $7 \mathrm{M} 4$ & $8 \mathrm{M} 2$ & $14 \mathrm{M} 4$ & $16 \mathrm{M} 2$ & $7 \mathrm{~T} 4^{b}$ & $4 \mathrm{M} 2^{c}$ & $13 \mathrm{~T} 2^{c}$ & $2 \mathrm{~T} 2^{d}$ & $3 \mathrm{~T} 2^{d}$ \\
\hline Erythritol & - & - & - & + & - & - & - & - & - & - & - \\
\hline D-Arabinose & - & - & - & - & + & - & - & - & - & - & - \\
\hline L-Arabinose & + & + & - & - & + & - & + & + & + & - & - \\
\hline Ribose & + & + & - & + & + & - & + & + & + & + & + \\
\hline D-Xylose & + & - & - & - & + & - & - & + & - & + & + \\
\hline Adonitol & - & - & - & + & + & - & - & - & - & - & - \\
\hline Galactose & + & - & - & + & + & - & + & + & + & + & - \\
\hline D-Mannose & + & + & - & + & + & - & + & + & + & + & + \\
\hline L-Sorbose & + & - & - & - & - & - & - & - & - & - & - \\
\hline Rhamnose & + & + & - & - & - & - & + & + & + & - & - \\
\hline Dulcitol & - & - & - & - & + & - & - & - & - & - & - \\
\hline Inositol & + & + & - & + & + & - & + & + & + & - & - \\
\hline Mannitol & + & + & - & + & + & + & + & + & + & + & + \\
\hline Sorbitol & + & - & - & + & + & - & + & + & + & - & - \\
\hline$\alpha$-Methyl-D-glucoside & + & + & - & - & - & - & + & + & + & - & + \\
\hline$N$-Acetyl glucosamine & + & + & - & + & + & - & + & + & + & + & + \\
\hline Amygdaline & + & + & - & - & + & - & + & + & - & - & - \\
\hline Arbutine & + & + & - & + & + & - & + & + & + & - & - \\
\hline Esculine & + & + & - & + & + & - & + & + & + & + & + \\
\hline Salicine & + & + & - & + & + & - & + & + & + & - & - \\
\hline Cellobiose & + & + & - & - & + & - & + & + & + & + & + \\
\hline Maltose & + & + & - & + & - & + & + & + & + & + & + \\
\hline Lactose & + & - & - & - & - & - & - & - & - & - & - \\
\hline Melibiose & + & - & - & - & - & - & - & - & - & - & - \\
\hline Saccharose & + & + & - & + & - & + & + & + & + & + & + \\
\hline Trehalose & + & + & - & + & + & + & + & + & + & + & + \\
\hline Melezitose & - & - & - & - & - & - & - & - & - & + & + \\
\hline D-Raffinose & + & - & - & - & - & - & - & - & - & - & - \\
\hline Amidon & - & + & - & - & - & - & + & + & - & + & + \\
\hline Glycogen & - & + & - & - & - & - & + & + & - & + & + \\
\hline Xylitol & - & - & - & + & - & + & - & - & - & - & - \\
\hline ß-Gentiobiose & + & + & - & - & + & - & - & + & - & - & + \\
\hline D-Turanose & - & + & + & - & - & - & + & + & + & + & + \\
\hline D-Lyxose & - & - & - & + & + & - & - & - & - & - & - \\
\hline D-Tagatose & - & + & - & - & - & - & + & + & + & - & - \\
\hline L-Fucose & + & - & - & + & + & - & - & - & - & - & - \\
\hline D-Arabitol & + & - & - & - & + & - & - & - & - & - & - \\
\hline L-Arabitol & - & - & - & + & + & - & - & - & - & + & - \\
\hline 2-Ceto-gluconate & + & - & + & + & + & - & - & - & - & - & + \\
\hline 5-Ceto-gluconate & + & - & - & + & - & - & - & - & - & - & - \\
\hline
\end{tabular}

${ }^{a}$ All isolates listed in the table were able to use glycerol, D-glucose, D-fructose, and gluconate as single carbon source, and none could utilize Lxylose, $\beta$-methyl-xyloside, $\alpha$-methyl-D-mannoside, inuline or D-fucose.

${ }^{b}$ RAPD P2 representative.

${ }^{c}$ RAPD P3 representatives.

${ }^{d}$ RAPD P4 representatives.

temperatures, culturable organisms were in the range of $10^{5} \mathrm{CFU}$ per gram of compost: $(6.7 \pm 3.0) \times 10^{5}$ and $(3.1 \pm 1.3) \times 10^{5}$, respectively.

The microorganisms presumptively capable of PCL degradation, present in the cultures on PCLM of the different samples, were isolated. The cultures were observed after different incubation periods ( $24 \mathrm{~h}$ to 15 days) in order to determine distinct colony morphologies and the presence of a clear zone around the colony, indicative of PCL degradation. On PCLM agar most of the isolates formed small colonies that, nevertheless, could be distinguished by their shape (margin and elevation), color, and brightness. This procedure resulted in the purification of 30 isolates which were characterized phenotypically and grouped using RAPD analysis. The results obtained for PCL, starch, Tween-80 and gelatin degradation, and growth at $30^{\circ} \mathrm{C}$ or $50^{\circ} \mathrm{C}$, were consistent with RAPD-based clustering (Table 1; Fig. 1). 
Characterization of thermophilic and mesophilic isolates. Based on the $16 \mathrm{~S}$ rDNA sequence analysis, the closest phylogenetic neighbors of mesophilic bacteria isolated during this study were members of the genera Acinetobacter, Pseudomonas, Burkholderia, Bacillus, Serratia, Staphylococcus, Pandoraea, and Klebsiella, while all the thermophiles were observed to belong to the genus Bacillus (Table 1; Fig. 2). The phenotypic characterization and RAPD profiling were consistent with $16 \mathrm{~S}$ rDNA-based phylogenetic analysis. These results clearly evidenced a higher taxonomic diversity for mesophiles than for thermophiles. Microbial communities of activated sludge differ amongst each system [32]; however, some mesophilic organisms isolated during this study, mainly Acinetobacter spp., are common inhabitants of such environments [2, 27].

Thermophilic bacteria isolated during this study could be divided into three RAPD groups, designated P2, P3, and P4. According to the genotypic analysis, the same genotypes, mainly RAPD P2, of thermophilic bacteria were isolated from different samplings, when distinct organisms indicated by different morphotypes were isolated. The consecutive selection of those isolates, which reflects the low diversity of culturable thermophilic bacteria, was due to the pleiomorphic character of the colony morphology. As was observed during the present study, the colony morphology of these organisms changes with the age of the culture. According to the $16 \mathrm{~S}$ rDNA sequence analysis, the closest phylogenetic relatives of the isolates in groups RAPD P2 and RAPD P3 were members of the species Bacillus licheniformis, while the other thermophiles are mostly related to the recently described species Bacillus gelatini [3]. Studies focused on man-made high-temperature environments report the isolation of organisms affiliated to a restricted group of genera. Prokaryotes found in environments such as solid waste or sewage sludge composts and thermobiotic wastewater treatment systems comprise Gram-positive bacteria belonging to the genera Thermus, Streptomyces, Thermonospora, Clostridium, Bacillus, and/or Geobacillus [1, 10, 12, 19, 28]. However, a higher diversity of thermophilic or thermotolerant organisms in such environments is evidenced by other studies. For example, the presence of thermophilic beta-subclass Proteobacteria has been evidenced using either culture-independent methods [12] or enrichment approaches $[14,16,25]$. It is also interesting to note that Caenibacterium thermophilum $\mathrm{N} 2-680^{\mathrm{T}}$ that was enriched at $50^{\circ} \mathrm{C}$ from composted sewage sludge of a wastewater treatment plant, using mineral medium with PCL [15], is able to degrade the aliphatic poly- esters used in the present work, though no member of this species was isolated in this study.

Biodegradative and nutritional properties of thermophilic and mesophilic isolates. Apparently, the capability of the isolates to degrade either of the PCLs tested, Capa 2054 and Capa 4101, did not depend on the molecular weight or chemical structure of the polymer, since no apparent correlation could be established between the type of PCL used for isolation and the genotype recovered, as was observed for RAPD P2. Moreover, the isolates could degrade both PCLs tested, independent of which was used for isolation.

Although the criterion used for the selection of isolates was the ability to degrade PCL, as indicated by a clear zone around the colony, it was observed that after purification some bacteria did not show the ability to degrade the polymers. Indeed, the selected colonies could represent a mixture of organisms and not a single isolate as assumed, explaining the apparent capacity to degrade the polymer. Alternatively, organisms may have lost the capacity to degrade the polyesters during laboratory transfers, as has been reported before [30].

Each isolate was also tested for extracellular lipolytic, proteolytic, and amylolytic activities using, respectively, Tween-80, gelatin, and starch as substrates (Table 1). Most of the isolates purified during this study could degrade one or more of these polymers. Gelatin was degraded by isolate $8 \mathrm{M} 2$ and by bacilli of RAPD groups P1 and RAPD P4. The simultaneous ability to degrade starch and PCL observed in B. licheniformis isolates could have important consequences for plastic biodegradability, since the production of multicomponent materials containing starch and synthetic polymers represents an important alternative in the production of biodegradable plastics [6].

Among the PCL-degraders, only two mesophilic isolates, 7M4 and 16M2, were lipase (Tweenase)-negative. In fact, it is described that crude extracts of bacterial lipases can degrade various polyesters [8, 22, 29]. These results suggest that the biodegradation of polyesters does not require specialized enzymes and/or pathways, and that they are readily eliminated from the environment. PCL-degrading organisms isolated during this study were phylogenetically closely related to the genera Burkholderia, Pseudomonas, Acinetobacter, Staphylococus, and Bacillus. Confirming previous studies with bacterial and synthetic polyesters [17, 30], the present report supports the conclusion that degradation of such polymers is performed by a phylogenetically diverse group of organisms.

The carbohydrate-based nutritional pattern of isolates affiliated to different species and/or genera was 
assessed, testing the ability to use 49 different compounds as sole carbon source. Most of the organisms revealed a versatile nutritional pattern, being able to use 20 or more of the carbon sources tested (Table 2). In contrast, some isolates were unable to use most or all the carbon sources tested: isolate $2 \mathrm{M} 2$ could use only glycerol and gluconate; isolate 6M4 used only L-arabinose; isolate 13M4 used only mannose; and isolate $12 \mathrm{M} 4$ did not grow on any of the carbohydrates tested. Although these results may be attributed to the need for specific growth requirements, it can also reflect the inability of these bacteria to use sugars or polyols as carbon sources.

Despite the fact that high temperature may favor the degradation of polymers [18], culturable thermobiota showed a poor taxonomic diversity compared with mesophilic isolates. However, such apparent poor diversity may not reflect the real situation, as has been evidenced by previous reports using enrichment methods or culture-independent approaches.

Thermophilic bacilli isolated throughout this study were able to grow at $30^{\circ} \mathrm{C}$ and at $50^{\circ} \mathrm{C}$, showed lipolytic, amylolytic, and proteolytic activities and a considerable nutritional versatility (Tables 1,2 ). Altogether, these phenotypic traits are indicative of the important role that these organisms may have during the whole composting process, regardless of which temperature stage is occurring. Moreover, other properties such as fast growth, swarming, and endospore-forming capacity may explain the excellent fitness of these thermophilic organisms in a nutrient-rich environment with considerable temperature fluctuations.

\section{ACKNOWLEDGMENT}

The authors thanks Solvay, UK, for the poly \&-caprolactones.

\section{Literature Cited}

1. Beffa T, Blanc M, Lyon P-F, Vogt G, Marchiani M, Fischer JL (1996) Isolation of Thermus strains from hot composts $\left(60^{\circ} \mathrm{C}\right.$ to $80^{\circ} \mathrm{C}$ ). Appl Environ Microbiol 62:1723-1727

2. Carr EL, Kämpfer P, Patel BKC, Gürtler V, Seviour RJ (2003) Seven novel species of Acinetobacter isolated from activated sludge. Int J Syst Evol Microbiol 53:953-963

3. De Clerck E, Rodríguez-Díaz M, Vanhoutte T, Heyrman J, Logan NA, De Vos P (2004) Anoxybacillus contaminans sp. nov. and Bacillus gelatini sp. nov., isolated from contaminated gelatin batches. Int J Syst Bacteriol (in press)

4. Doetsch RN (1981) Determinative methods of light microscopy. In: Gerhardt P, et al. (eds). Manual of methods of general bacteriology. Washington, DC: American Society for Microbiology, pp 21-23

5. Felsenstein J (1993) PHYLIP (phylogenetic inference package), version 3.5.1 Seattle: Department of Genetics, University of Washington
6. Gordon SH, Imam SH, Greene RV (1996) Starch-based plastics (measurement of biodegradability). In: Salamone JC (ed). Polymeric materials encyclopedia, vol 10. Boca Raton, FL: CRC Press, pp 7885-7891

7. Hall TA (1999) BioEdit: A user-friendly biological sequence alignment editor and analysis program for Windows 95/98/NT. Nucleic Acids Symp Ser 41:95-98

8. Jaeger KE, Steinbuchel A, Jendrossek D (1995) Substrate specificities of bacterial polyhydroxyalkanoate depolymerases and lipases: Bacterial lipases hydrolyze poly(omega-hydroxyalkanoates). Appl Envir Microbiol 61:3113-3118

9. Jukes TH, Cantor CR (1969) Evolution of protein molecules. In: Munro HN (ed). Mammalian protein metabolism. New York: Academic Press, pp 21-132

10. Kleeberg I, Hetz C, Kroppenstedt RM, Müller R-J, Deckwer W-D (1998) Biodegradation of aliphatic-aromatic copolyesters by Thermomonospora fusca and other thermophilic compost isolates. Appl Environ Microbiol 64:1731-1735

11. Kumar S, Tamura K, Jakobsen IB, Nei M (2001) MEGA2: Molecular evolutionary genetics analysis software. Bioinformatics 17:1244-1245

12. LaPara TM, Nakatsu CH, Pantea L, Alleman JE (2000) Phylogenetic analysis of bacterial communities in mesophilic and thermophilic bioreactors treating pharmaceutical wastewater. Appl Environ Microbiol 66:3951-3959

13. Maidak BL, Cole JR, Lilburn TG, Parker CT Jr, Saxman PR, Farris R, et al. (2001) The RDP-II (Ribosomal Database Project). Nucleic Acids Res 29:173-174

14. Manaia CM, Moore ERB (2002) Pseudomonas thermotolerans sp. nov., a thermotolerant species of Pseudomonas. Int J Syst Evol Microbiol 52:2203-2209

15. Manaia CM, Nunes OC, Nogales B (2003) Caenibacterium thermophilum gen. nov., sp. nov., isolated from a thermophilic aerobic digester of municipal sludge. Int J Syst Evol Microbiol 53:1375-1382

16. Manaia CM, Nogales B, Nunes OC (2003) Tepidiphilus margaritifer gen. nov., sp. nov., isolated from a thermophilic aerobic digester. Int J Syst Evol Microbiol 53:1405-1410

17. Mergaert L, Swings J (1996) Biodiversity of microorganisms that degrade bacterial and synthetic polyesters. J Ind Microbiol 17:463-469

18. Müller R, Antranikian G, Maloney S, Sharp R (1998) Thermophilic degradation of environmental pollutants. Adv Biochem Eng Biotechnol 61:155-169

19. Peters S, Koschinsky S, Shwieger F, Tebbe CC (2000) Succession of microbial communities during hot composting as detected by PCR-single-strand-conformation polymorphism-based genetic profiles of small-subunit rRNA genes. Appl Environ Microbiol 66:930-936

20. Polprasert C (1996) Organic waste recycling: Technology and management, 2nd edn. Chichester: Wiley

21. Ponti C, Sonnleitner B, Fiechter A (1995) Aerobic thermophilic treatment of sewage sludge at pilot plant scale. 2. Technical solutions and process design. J Biotechnol 38:185-192

22. Pranamuda H, Tokiwa Y, Tanaka H (1995) Microbial degradation of an aliphatic polyester with a high melting point, poly(tetramethylene succinate). Appl Environ Microbiol 61:1828-1832

23. Rainey FA, Ward-Rainey N, Kroppenstedt RM, Stackebrand E (1996) The genus Nocardiopsis represents a phylogenetically coherent taxon and a distinct actinomycete lineage: Proposal of Nocardiopsaceae fam. nov. Int J Syst Bacteriol 46:1088-1092 
24. Santos P, Pinhal I, Rainey FA, Empadinhas N, Costa J, Fields B (2003) Gamma-Proteobacteria Aquicella lusitana gen. nov., sp. nov., and Aquicella siphonis sp. nov. infect protozoa and require activated charcoal for growth in laboratory media. Appl Environ Microbiol 69:6533-6540

25. Shooner F, Tyagi RD (1995) Microbial ecology of simultaneous thermophilic microbial leaching and digestion of sewage sludge. Can J Microbiol 41:1071-1080

26. Smibert RM, Krieg NR (1981) General characterization. In: Gerhardt P, et al. (eds). Manual of methods for general bacteriology. Washington, DC: American Society for Microbiology, pp 409443

27. Snaidr J, Amann R, Huber I, Ludwig W, Schleifer KH (1997) Phylogenetic analysis and in situ identification of bacteria in activated sludge. Appl Environ Microbiol 63:28842896

28. Strom PF (1985) Identification of thermophilic bacteria in solidwaste composting. Appl Environ Microbiol 50:906-913
29. Suyama T, Tokiwa Y (1997) Enzymatic degradation of an aliphatic polycarbonate, poly(tetramethylene carbonate). Enzyme Microbial Technol 20:122-126

30. Suyama T, Tokiwa Y, Ouichanpagdee P, Kanagawa T, Kamagata $Y$ (1998) Phylogenetic affiliation of soil bacteria that degrade aliphatic polyesters available commercially as biodegradable plastics. Appl Environ Microbiol 64:5008-5011

31. Thompson JD, Gibson JT, Plewniak F, Jeanmougin F, Higgins DG (1997) The ClustalX windows interface: Flexible strategies for multiple sequence alignment aided by quality analysis tools. Nucleic Acids Res 24:4876-4882

32. van Heerden J, Ehlers MM, Cloete TE (2001) Biolog for the determination of microbial diversity in activated sludge systems. Water Sci Technol 43:83-90

33. Wiedmann-al-Ahmad M, Tichy HV, Schon G (1994) Characterization of Acinetobacter type strains and isolates obtained from wastewater treatment plants by PCR fingerprinting. Appl Environ Microbiol 60:4066-4071 